\title{
DERBY DIARIES
}




\title{
A SELECTION FROM
}

\author{
THE DIARIES \\ $\mathrm{OF}$ \\ EDWARD HENRY STANLEY, I5th \\ EARL OF DERBY \\ (I826-93) \\ BETWEEN SEPTEMBER \\ I869 AND MARCH I878 \\ edited by \\ JOHN VINGENT
}

CAMDEN FIFTH SERIES

VOLUME 4 (1994)

LONDON

OFFICES OF THE ROYAL HISTORICAL SOCIETY

UNIVERSITY COLLEGE LONDON

GOWER STREET WCI

1994 
(C) The Earl of Derby (text)

The Royal Historical Society (additional matter)

British Library Cataloguing in Publication Data

Diaries of Edward Henry Stanley, I5th Earl of Derby (1826-93); Selections

(Camden fifth series; v.3)

I. History - Periodicals

I. Royal Historical Society II Series

ISBN o-86193-137-9

Printed and bound in Great Britain by Butler \& Tanner Ltd., Frome and London 


\section{To Kenneth and Elizabeth in gratitude}




\section{GONTENTS}

AGKNOWLEDGEMENTS . . . . . . . . . . . . . viii

Abrreviations. $\quad . \quad$. $\quad . \quad$. . . . . .

INTRODUGTION . $\quad . \quad+\quad, \quad . \quad$. $\quad . \quad$. $\quad . \quad$ I

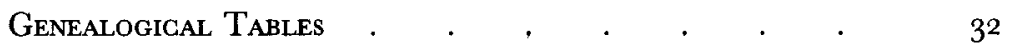

The Diaries

I869 . . . . . . . . . . . .

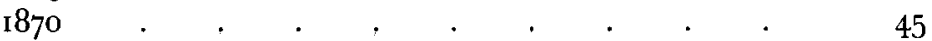

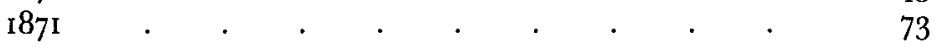

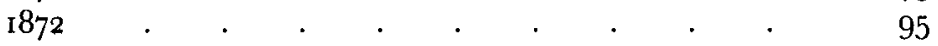

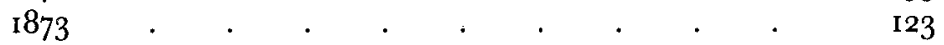

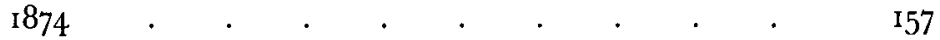

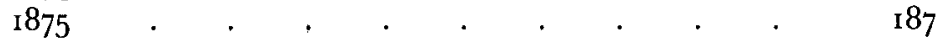

$1876 \quad . \quad . \quad . \quad . \quad . \quad . \quad . \quad . \quad . \quad . \quad 263$

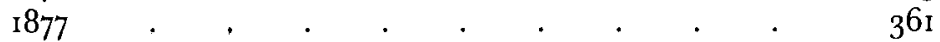

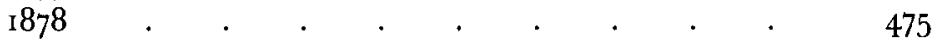

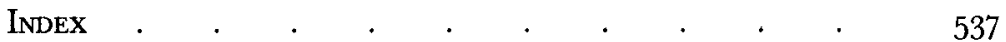

